\title{
QUERCETIN AND ELLAGIC ACID IN GASTRIC ULCER PREVENTION: AN INTEGRATED SCHEME OF THE POTENTIAL MECHANISMS OF ACTION FROM IN VIVO STUDY
}

\author{
SOHEIR E KOTOB*, ALAA H SAYED, SAFAA H MOHAMED, HANAA H AHMED
}

Department of Hormones, National Research Centre, Dokki, Giza, Egypt. Email: soheir1010@hotmail.com

Received: 14 August 2017, Revised and Accepted: 09 October 2017

ABSTRACT

Objective: The present study was initiated to describe the gastroprotective role of quercetin (Qu) and ellagic acid (EA) on aspirin-induced gastric ulcer (GU) in rats.

Methods: Forty adult female albino rats of Wistar strain were distributed into: Control group, GU group, Omeprazole group, Qu group, and EA group. Gross examination, biochemical analyses including serum adrenocorticotropic hormone (ACTH), serotonin (ST), ferritin, heme oxygenase-1 (HO-1), interleukin-2 (IL-2), advanced glycosylation end products (AGEs), and fibronectin (FN) levels were estimated. Moreover, histopathological and histochemical examinations of stomach tissue samples were carried out.

Results: Gross examination of gastric mucosa of rats in GU group revealed hyperemia of the stomach mucosa. Furthermore, rats in GU group experienced a significant rise in serum ACTH, ferritin, HO-1, IL-2 and AGEs levels accompanied with significant drop in serum ST and FN levels versus control counterparts. Pre-treatment of GU group with Omeprazole, Qu or EA caused marked improvement in the measured biochemical parameters. Histopathological and histochemical examinations of stomach tissue samples documented the protective action of Omeprazole, Qu and EA with different degrees against GU caused by aspirin.

Conclusion: As a conclusion to this study, we can state that both Qu and EA have gastroprotective effect against aspirin-induced GU in rat model. Of note, Qu showed superior impact than EA as an antiulcer agent in this study. The corresponding mechanisms are speculated to be associated with inhibiting stress-induced gastric lesion, attenuating the oxidative stress, iron chelation and blunting ferritin level, modulating inflammatory cascade, and promoting the healing process.

Keywords: Gastric ulcer, Omeprazole, Quercetin, Ellagic acid, Aspirin, Rats.

(C) 2018 The Authors. Published by Innovare Academic Sciences Pvt Ltd. This is an open access article under the CC BY license (http://creativecommons. org/licenses/by/4. 0/) DOI: http://dx.doi.org/10.22159/ajpcr.2018.v11i1.21991

\section{INTRODUCTION}

The incidence of peptic ulcer has steadily declined throughout the world [1]. Peptic ulcers are a broad term that includes ulcers of gastrointestinal (GI) tract. The formation of peptic ulcers is due to the presence of acid, peptic activity in gastric juice and a breakdown in mucosal defenses [2]. The pathogenesis of gastric lesions has a multifactorial origin including oxidative stress, DNA deterioration and a blunting glutathione (GSH) concentration in gastric mucosal cells [3]. Nonsteroidal anti-inflammatory drugs (NSAIDs) are recognized as the most common etiological factors associated with peptic ulcer [4]. Aspirin is one of the NSAIDs which injures the GI mucosa due to oxygen-derived free radicals such as superoxide $\mathrm{O}^{2} \cdot$ - anion and hydroxyl radical-mediated injury of this mucosa [5]. The incidence of serious GI adverse events due to aspirin consumption is approximately one case per 1000 persons/year in overall population [6]. Despite its relatively low risk for GI bleeding, the millions of aspirin users worldwide determine an important increase in the number of drug-related GI complications [7].

The functional integrity of gastric mucosa depends on the balance between aggressive modulators and protective mechanisms. Thus, the success of gastric pharmacological therapy relies not only on the blockage of acidic secretion but also on motivation of the protective modulators of the gastric mucosa [8]. Proton pump inhibitors (PPIs) $\left(\mathrm{H}^{+} \mathrm{K}^{+}\right.$-ATPase inhibitors) such as Omeprazole, Lansoprazole, Pantoprazole, and Rabeprazole are a family of prodrugs that can be activated by low $\mathrm{pH}$ [9]. These are greatly effective in inhibiting acidic secretion from gastric cells, and therefore they are highly used in the treatment of gastric ulcers (GUs) and reflux esophagitis [10]. In addition, PPIs have been reported to exert anti-inflammatory effects unrelated to the inhibition of gastric acid release, although the behind mechanisms have remained obscure [11].

Phytogenic candidates have traditionally been used by herbalists and indigenous healers for treatment of GU. Flavonoids are polyphenolic compounds which exhibit different biological activities. Quercetin (Qu) (2-(3,4-dihydroxyphenyl)-3,5,7-trihydroxy-4H-chromen-4-one) is the most common flavonoid compound biosynthesized by plants. $\mathrm{Qu}$ has been reported to have a wide range of pharmacological and biological functions [12]. It is present in onions, apples, tea as well as red wine [13] and has an antioxidant action as it directly scavenges the superoxide anion and represses many superoxide-generating enzymes such as xanthine oxidase [14] and the neutrophil membrane nicotinamide adenine dinucleotide phosphate-oxidase (NADPH) oxidase complex [15]. It has been used as traditional therapy for many inflammatory disorders [16]. An interesting issue of the antiulcer action of $\mathrm{Qu}$ is the suppression of Helicobacter pylori growth in a dosedependent manner in vitro [17]. Of note, H. pylori and NSAIDs are the most causative factors for GU disease [18].

Ellagic acid (EA) (2,3,7,8-tetrahydroxy [1] benzopyrano [5,4,3-cde] [1] benzopyran-5,10-dione) is one of the naturally occurring polyphenols present in raspberries, strawberries, cranberries, walnuts, Indian gooseberries, pecans, pomegranates, and others mainly in the form of ellagitannins [19]. EA possesses a wide spectrum of pharmacological activities such as anticancer [20], antiallergic [21], antimalarial [22], antiwrinkle [23], antiglycative, anti-inflammatory [24], and antioxidant [25]. In fact, EA has been found to exhibit a potential scavenging action on superoxide anion and hydroxyl anion in vitro [26]. EA can produce a dose-dependent bactericidal effect on $H$. pylori [27]. It provides strong 
protection to colonic mucosa during the inflammatory response to dextran sulfate sodium-induced ulcerative colitis, and it can decrease the gross mucosal damage by the inhibition of myeloperoxidase activity and lipid peroxidation [28].

The present study was constructed to address the protective role of $\mathrm{Qu}$ and EA in aspirin-induced GU in rat model with special focus on their mechanisms of action.

\section{MATERIALS AND METHODS}

\section{Materials}

\section{Drugs and chemicals}

Aspirin was obtained from German Remedies Ltd., Mumbai, India. Omeprazole, QU and EA were purchased from Sigma Chemical Co. St. Louis, MO, USA. All other chemicals used in this study were obtained commercially, and they were of analytical grade.

\section{Animals and experimentation}

This study was conducted in accordance with the principles and guidelines of the Ethical Committee for animal care and protection of the National Research Centre, Egypt.

Forty adult female albino rats of Wistar strain weighing $130 \pm 10 \mathrm{~g}$ at 90 days of age were enrolled in this study. The animals were acquired from the Animal House Colony of the National Research Centre, Giza, Egypt. The animals were housed in polypropylene cages (8 rats/cage) in an environmentally controlled clean air room with a temperature of $24 \pm 1^{\circ} \mathrm{C}$, a $12 \mathrm{~h}$ light $/ 12 \mathrm{~h}$ dark cycle, a relative humidity of $60 \pm 5 \%$ and free access to tap water and standard rodent chow. Rats were allowed to adapt to these conditions for 2 weeks before the commencement of the experiment. After the acclimatization period, rats were distributed into: Group 1: Control group, Group 2: GU group induced by a single dose of aspirin (150 mg/kg b.wt) [29], Group 3: Omeprazol group which orally received Omeprazol (20 mg/kg b.wt) [30] daily for 1 week before induction of GU, Group 4: QU group which orally received Qu $(50 \mathrm{mg} / \mathrm{kg}$ b.wt) [31] daily for 1 week before induction of GU, and Group 5: EA group which received orally EA (7 mg/kg b.wt) [32] daily for 1 week before induction of GU. After $6 \mathrm{~h}$ from aspirin administration, all animals were subjected to light anesthesia by diethyl ether according to the method of Van Herck et al. [33] Then, the blood samples were collected using orbital sinus technique. The blood samples were left to clot in a clean, dry test tube and then centrifuged at $1800 \times \mathrm{g}$ for $10 \mathrm{~min}$. at $4^{\circ} \mathrm{C}$ to obtain sera. The clear serum samples were preserved at $-20^{\circ} \mathrm{C}$ till the time of use in the biochemical analyses.

After collection of the blood samples, the animals were sacrificed by cervical dislocation and the stomach from all experimental animals were quickly excised, washed in saline, blotted dry and prepared for gross examination, histopathological and histochemical investigations.

\section{Methods}

\section{Gross examination}

Fresh stomach from each rat was taken and opened along the greater curvature. The ulcer index (UI) was calculated according to a method of Ganguly [34]:

Ulcer index $=10 / \mathrm{X}$

Where $\mathrm{X}=$ Total mucosal area/Total ulcerated area.

Based on its intensity, the ulcer was given score as follows:

$0=$ No ulcer, $1=$ Superficial mucosal erosion, $2=$ Deep ulcer or transmural necrosis, $3=$ Perforated or penetrated ulcer.

The number of ulcers were counted using a magnifying lens and then measured with a caliper to determine the diameter. The percentage of inhibition with Omeprazole, $\mathrm{Qu}$, and EA in the pre-treated GU groups was calculated according to the formula of Suzuki et al. [35]:

$$
\% \text { inhibition }=\frac{\text { UI control }- \text { UI treated }}{\text { UI control }} \times 100
$$

Where UI stands for ulcer index.

\section{Biochemical analyses}

Serum adrenocorticotropic hormone (ACTH) level was quantified using rat enzyme-linked immunosorbent assay (ELISA) kit purchased from DRG international Inc. (USA) according to the method of Odell et al. [36] Serum serotonin (ST) level was assessed using rat ELISA kit purchased from WKEA, Med Supplies Crop, (China) according to manufacturer's instructions. Serum ferritin level was estimated using rat ELISA kit purchased from Immunospec Corporation, CA (Netherlands), according to White et al. [37] method. Serum heme oxygenase-1 (HO-1), advanced glycosylation end products (AGEs) and fibronectin (FN) levels were determined using rat ELISA kits purchased from Glory Science Co., Ltd, (USA) according to manufacturer's instructions. Serum interleukin-2 (IL-2) level was measured using rat ELISA kit purchased from Diaclone a tepnel Company (France) according to manufacturer's instructions.

\section{Histopathological and histochemical investigations}

After recording the ulcer parameters of the stomach of rats in all groups, sections of the gastric tissue were fixed in $10 \%$ formalin for $24 \mathrm{~h}$. The fixed specimens were embedded in paraffin, sectioned ( $5 \mu \mathrm{m})$ using Leica rotary microtome and stained with hematoxylin and eosin for histological assessment of the gastric mucosa changes [38]. Periodic acid Schiff method [39] was applied for a demonstration of the mucus materials in the mucosa of the stomach.

\section{Statistical analysis}

The experimental results were represented as arithmetic means with their standard errors (mean \pm standard error). Data were analyzed by one-way analysis of variance using the Statistical Package for the Social Sciences (SPSS) program, version 14 followed by least significant difference to compare significance between groups [40]. Statistical analysis was made with the statistical software Microcal Origin (version 14, Microcal Software Inc., Northampton, USA). The level of significance was set at $\mathrm{p}<0.05$.

\section{RESULTS}

\section{Gross assessment of gastric mucosal injury}

No mucosal lesions are recorded in rats of the control group. Administration of aspirin displayed remarkable hyperemia in the stomach of rats of this group. In the GU groups pre-treated with Omeprazole, Qu, or EA, hyperemia appeared to be very slight compared to untreated GU group. The UI in GU group was $8.7 \pm 0.33$, and the ulcer indices of rats that pre-treated with Omeprazole, $\mathrm{Qu}$ or EA were $2.69 \pm 0.24,1.44 \pm 0.37$ and $1.84 \pm 0.34$, respectively, representing a significant reduction versus the untreated GU group (Table 1). Percentages of inhibition resulting from pre-treatment with Omeprazole, Qu, or EA were 69.08\%, 83.44\%, and 78.85\%, respectively, documenting the findings of the ulcer indices. These observations indicated that Omeprazole, Qu, and EA exhibited significant protective action against gastric injury caused by aspirin.

\section{Biochemical data}

The data in Table 2 illustrate the effect of pre-treatment with Omeprazole, Qu, and EA on serum ACTH, ST, ferritin, HO-1, IL-2, AGEs, and FN levels in GU bearing rats. The GU group revealed significant elevation $(\mathrm{p}<0.05)$ in serum ACTH, ferritin, HO-1, IL-2, and AGEs levels accompanied with significant decline $(\mathrm{p}<0.05)$ in serum ST and FN levels versus those in the control group. Pre-treatment of GU group with Omeprazole led to significant reduction $(p<0.05)$ in serum ACTH, 
ferritin, HO-1, IL-2, and AGEs levels. Meanwhile, it induced insignificant enhancement ( $p>0.05)$ in serum ST and FN levels as compared with the untreated GU group. GU bearing group pre-treated with Qu experienced significant drop $(\mathrm{p}<0.05)$ in serum ACTH, ferritin, and HO-1 levels. While, it displayed insignificant decrease $(p>0.05)$ in IL-2 and AGEs levels associated with insignificant rise $(p>0.05)$ in serum $F N$ level relative to the untreated GU group. Treatment with EA prior induction of GU evoked insignificant decrease $(p>0.05)$ in serum ACTH and IL-2 levels accompanied with insignificant increase $(\mathrm{p}>0.05)$ in serum ST and FN levels in respect with the untreated GU group. However, it caused significant suppression $(\mathrm{p}<0.05)$ in serum ferritin, HO-1, and AGEs levels (Table 2).

\section{Histopathological findings}

Histological examination of section of stomach tissue of the control rat showed normal structural organization of the stomach (Fig. 1a). However, microscopic examination of section of the stomach tissue of rat administered aspirin revealed necrosis of the surface mucous cells and fundus glands as well as hemorrhage in the mucosal layer. Moreover, the mucous cells appeared to be pyknotic and desquamated from mucosa and the necrosis extended to the body of the fundus glands (Fig. 1b).

Examination of section of the stomach tissue of rat treated with Omeprazole prior induction of GU showed areas of hemorrhage and a little degenerative superficial epithelial cells and the remaining

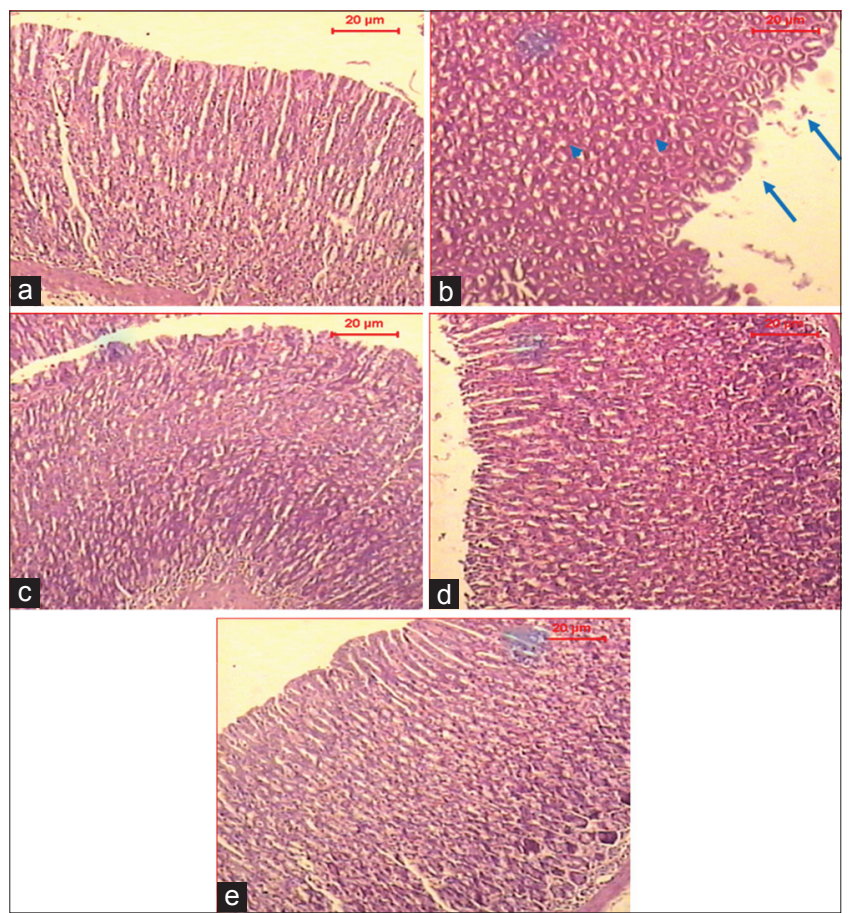

Fig. 1: Optical micrograph of stomach tissue sections of (a): Control rat showing the normal structure of mucosa, (b): Gastric ulcer bearing rat showing a necrosis of surface mucous cells and fundus glands (arrows) and hemorrhage in the mucosal layer. Necrosis has been shown to be extended to the body of the fundus glands. Surface mucous cells are pyknotic and desquamated from mucosa (arrowhead), (c): Omeprazole pretreated rat showing areas of hemorrhage and a little degenerative superficial epithelial cells. The remaining cells appear more or less like control, (d): Quercetin pre-treated rat showing few degenerative area in the outer surface of mucosa (arrow) while its lower part shows almost normal structure (arrowhead), and (e): Ellagic acid pre-treated rat showing little degenerative epithelial cells. The remaining cells appear more or less like control ( $\mathrm{H}$ and $\mathrm{E}$, scale bar $=0 \mu \mathrm{m})$ appeared more or less like control (Fig. 1c). Section of the stomach tissue of GU bearing rats pre-treated with Qu revealed few degenerative areas in the outer surface of mucosa while its lower part showed almost normal structure (Fig. 1d). In case of examination of stomach tissue section of GU bearing rats treated with EA prior induction of GU, the microscopic observation revealed little degenerative epithelial cells and the remaining appeared more or less like control (Fig. 1e).

Histochemical analysis of polysaccharides

Histochemical examination of section of stomach tissue of control rat showed polysaccharide materials that represent mucus in the gastric mucosa are mainly localized in the epithelium lining the stomach mucosa. The apical regions of these cells exhibited deep stainability, while the other cells of the gastric mucosa acquired pale stainability (Fig. 2a). Histochemical investigation of stomach tissue section of GU bearing rat showed mucus production in the surface epithelial and mucous neck cells as manifested by the pale or depletion of stainability (Fig. 2b). Examination of tissue section of stomach of Omeprazole pre-treated rat exhibited an increase in the polysaccharides of the surface epithelium and the mucous neck cells of the gastric mucosa. The degenerative parts of the mucosa displayed weak stainability (Fig. 2c). Investigation of stomach tissue sections of rats received $\mathrm{Qu}$, or EA prior induction of GU showed heterogeneous staining which is encountered

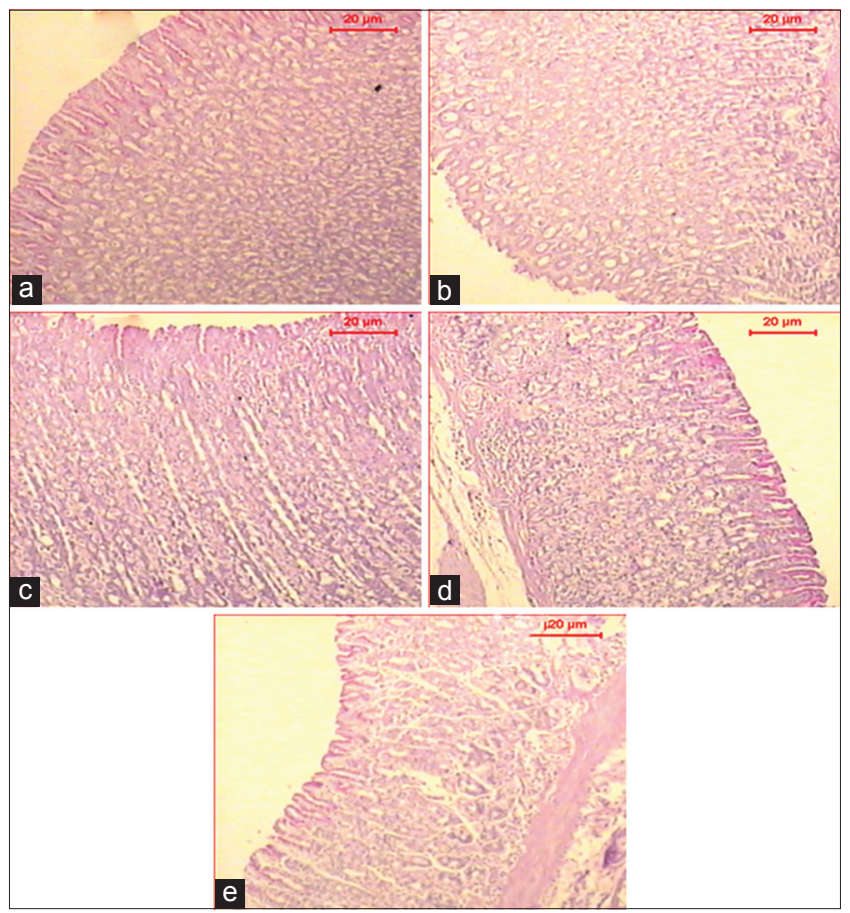

Fig. 2: Photomicrograph of tissue sections of stomach of (a) control rat showing that periodic acid-Schiff (PAS) positive materials in the gastric mucosa display dark pink stainability in the surface epithelial cells (long arrow) and in the mucous neck cells (short arrows). The surface of epithelial cells gives more intense stainability than the mucous neck cells. The other cells of the mucosa acquire pale stainability, (b) gastric ulcer

(GU) bearing rat showing that the polysaccharides in the surface epithelial and mucous neck cells acquire pale stainability (arrow), (c) Omeprazole pre-treated rat showing an increase in the polysaccharides of the surface epithelium and the mucous neck cells of the gastric mucosa. The degenerative parts of the mucosa display weak stainability, (d and e) GU bearing rats received quercetin or ellagic acid prior induction of GU showing encountered heterogeneous staining where the degenerated surface epithelial cells are almost devoided of stainable material, and the outer half of the mucosa is densely stained (PAS, scale bar $=20 \mu \mathrm{m}$ ) 
where the degenerated surface epithelial cells are almost devoided of stainable material, and the outer half of the mucosa is densely stained (Fig. 2d and e), respectively.

\section{DISCUSSION}

In recent years, herbal remedies exhibited man promising impact against peptic ulcer. It was, therefore, thought exciting to investigate the effectiveness of $\mathrm{Qu}$ and EA in the protection against GU induced by aspirin in rats. Regarding, the UI, the present data revealed that the administration of aspirin elicits severe gastric hemorrhagic erosions. Aspirin has been observed to cause mucosal injury by interfering with prostaglandin synthesis, enhancing acid secretion and back diffusion of $\mathrm{H}^{+}$ions, leading to overproduction of leukotrienes and other products of 5-lipoxygenase axis [41].

The GU group pre-treated with Omeprazole showed a significant decrease in UI compared to the untreated GU group. It has been demonstrated that Omeprazole significantly reduces GU formation induced by indomethacin. Omeprazole decreases ulcer formation in rabbit model by inhibiting gastric acid secretion. These findings indicated that gastric acid plays a key role in the promotion of GU in rabbits [42]

The present results indicated that the pre-treatment with $\mathrm{Qu}$ in GU bearing rats markedly ameliorates the UI caused by aspirin. Alkushi and Elsawy [43] cited that QU has antioxidant property and can protect gastric mucosa against indomethacin-induced GU.

Pre-treatment with EA in GU bearing rats markedly decreased the UI caused by aspirin. These data suggested that EA possesses ulcer-healing activity. EA showed the ability to potentiate healing of indomethacininduced GU in mice due to its capability to reduce neutrophils infiltration. The modulation of COX-pathway by EA helps in amplifying mucosal growth factors levels and preserving the balance of pro-/antiinflammatory cytokines levels to aggravate ulcer healing [32].

In the current study, significant rise in serum ACTH level in GU group has been recorded. This finding is congruent with Virchenko et al. [44]. The activation of hypothalamic-pituitary-adrenal (HPA) system under the conditions of stress-induced gastric lesion has been known leading to

Table 1: Effect of pre-treatment with Omeprazole, Qu, and EA on aspirin-induced gastric ulcer in rats as indicated by ulcer index and percentage of inhibition

\begin{tabular}{lll}
\hline Experimental groups & Ulcer index & Percentage of inhibition \\
\hline Control group & - & - \\
GU group & $8.7 \pm 0.33$ & - \\
Omeprazole group & $2.69 \pm 0.24^{*}$ & 69.08 \\
Qu group & $1.44 \pm 0.37^{*}$ & 83.44 \\
EA group & $1.84 \pm 0.34^{*}$ & 78.85 \\
\hline
\end{tabular}

Data expressed as mean \pm SE $(n=8) .{ }^{*} \mathrm{p}<0.05$ was considered statistically significant when compared to GU group, Qu: Quercetin, EA: Ellagic acid, GU: Gastric ulcer, SE: Standard error the elevated secretion of ACTH and corticosterone [45]. Such intensive increase of glucocorticoids in serum results in severe damage of gastric mucosa [46]. Hyperactivation of HPA system leads to the deep depletion of pituitary and adrenal glands activity and thereafter aggravation of ulcers [44]. Furthermore, the secretion of proinflammatory cytokines, under the stress conditions-induced gastric lesions, enhances the levels of ACTH and corticosterone [47].

Treatment of GU bearing rats with Omeprazole prior induction of GU produced significant inhibition in serum ACTH level. PPIs have been shown to prevent stress-related GI bleeding [48]. Therefore, the present study finding may explain the role of this family of drugs in conducting this effect through suppressing ACTH release.

GU group pre-treated with $\mathrm{Qu}$ exhibited a significant reduction in serum ACTH. Treatment with Qu at different dosages has been found to decrease the stress-induced elevation of corticosterone. Furthermore, $\mathrm{Qu}$ and its metabolites have been shown to influence the swimming stress-induced potentiation of HPA axis. Qu showed a potent action on the hypothalamus to reduce corticotropin-releasing factor (CRF) through downregulating CRF mRNA in the hypothalamus [49]. Hypothalamic CRF is the major and essential component of HPA cascade, and the reduction of this factor leads to an inhibition in the production of ACTH [13].

Pre-treatment of GU group with EA led to an insignificant drop in serum ACTH level. Naveen et al. [50] observed that flax seed extract, which has many polyphenolic compounds including EA, is capable to significantly decrease corticosterone level in mice exposed to chronic mild stress. This finding indicates the ability of EA to decrease the production of ACTH.

In this study, significant decrease in serum ST level has been registered in GU bearing group. Al Asmari et al. [51] observed that ethanolinduced gastric mucosal injury causes blunting in the levels of ST in gastric tissue. The severity of gastric ulceration was noted to rise with a decrease in gastric ST levels in different models of ulcers [52]. Furthermore, it has been suggested that the increased basal gastric acid in duodenal ulcer (DU) patients is linked to down secretion of ST (a probable physiological suppressor of the secretion gastric acid secretion) in the stomach [53]. Monoamines, dopamine, and ST which are extensively present in the GI tract have an important role in its physiological function involving acid and mucus secretions, mucus production, gastric motility, mucosal blood flow, and fluid secretion. Alterations in their levels have a profound manipulating action on the mucosal defense of the GI tract and exacerbation of ulcerations [54,55].

Pre-treatment of GU bearing rats with Omeprazole elicited insignificant increase in serum ST level. Omeprazole is used widely in the treatment of diseases linked to gastric acid secretion. There are documents from studies both in vitro and in vivo indicating that Omeprazole can inhibit the activity of cytochrome P-450 isoenzyme CYP2C19 (CYP2C19). It has been shown that the selective ST reuptake inhibitors Citalopram, Escitalopram, and Sertraline are all metabolized by CYP2C19 [56]. This explains the observed elevation in serum ST level on Omeprazole administration.

Table 2: Protective effect of Omeprazole, $Q u$, and EA against aspirin-induced gastric ulcer in rats manifested by biochemical analyses

\begin{tabular}{|c|c|c|c|c|c|c|c|}
\hline \multirow[t]{2}{*}{ Experimental groups } & \multicolumn{7}{|l|}{ Parameters } \\
\hline & АСТН (pg/ml) & ST (pg/ml) & Ferritin $(\mathrm{ng} / \mathrm{ml})$ & HO-1 (ng/L) & IL-2 (pg/ml) & AGEs (ng/L) & FN $(\mu \mathrm{g} / \mathrm{ml})$ \\
\hline Control group & $15.14 \pm 1.28$ & $57.8 \pm 5.7$ & $39.1 \pm 1.18$ & $3.7 \pm 0.42$ & $0.28 \pm 0.014$ & $833.3 \pm 55.6$ & $17.7 \pm 1.9$ \\
\hline GU group & $23.7 \pm 1.4^{\mathrm{a}}$ & $31.0 \pm 4.05^{\mathrm{a}}$ & $51.75 \pm 2.57^{\mathrm{a}}$ & $6.8 \pm 0.13^{\mathrm{a}}$ & $0.5 \pm 0.085^{a}$ & $1028.5 \pm 39.9^{a}$ & $11.0 \pm 1.07^{\mathrm{a}}$ \\
\hline Omeprazol group & $17.14 \pm 1.6^{b}$ & $35.7 \pm 3.58^{a}$ & $41.5 \pm 0.8^{b}$ & $4.5 \pm 0.34^{b}$ & $0.32 \pm 0.032^{\mathrm{b}}$ & $907.1 \pm 19.2 b$ & $12.6 \pm 0.9^{a}$ \\
\hline Qu group & $19.4 \pm 0.94^{\mathrm{ab}}$ & $46.3 \pm 2.2 \mathrm{a}^{\mathrm{b}}$ & $46.0 \pm 0.75^{\mathrm{abc}}$ & $4.68 \pm 0.31^{\mathrm{ab}}$ & $0.47 \pm 0.079^{\mathrm{a}}$ & $960.0 \pm 27.19^{a}$ & $12.7 \pm 0.4^{\mathrm{a}}$ \\
\hline EA group & $20.5 \pm 1.03^{\mathrm{a}}$ & $40.8 \pm 3.33^{a}$ & $46.0 \pm 0.75^{\mathrm{abc}}$ & $5.14 \pm 0.26^{\mathrm{ab}}$ & $0.43 \pm 0.004$ & $920.8 \pm 6.1^{\mathrm{b}}$ & $13.1 \pm 0.47^{\mathrm{a}}$ \\
\hline
\end{tabular}

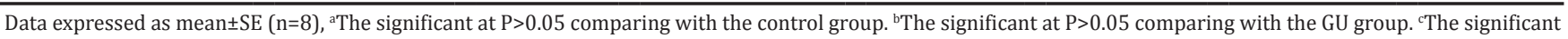
at P>0.05 comparing with Omeprazole group. Qu: Quercetin, EA: Ellagic acid, ACTH: Adrenocorticotropic hormone, ST: Serotonin, HO-1: Heme oxygenase-1, IL-2: Interleukin-2, AGES: Advanced glycosylation end products, FN: Fibronectin, GU: Gastric ulcer 
Treatment with Qu prior GU induction caused insignificant increase in serum ST level. Qu has a powerful effect on the modulation of serotonergic activity by ameliorating brain mitochondrial monoamine oxidase-A (MAO-A) activity. Qu metabolite, Qu 3-glucuronide, could attenuate the oxidative stress by counteracting the production of hydrogen peroxide associating MAO-A reaction [57]. In general, $\mathrm{Qu}$ could prevent the alterations in neurotransmitters levels, and this may contribute to the neuroprotective role of $\mathrm{Qu}[58]$.

In this study, GU group pre-treated with EA experienced insignificant enhancement in serum ST level. It has been demonstrated that acute oral administration of EA or extract contains EA causes modulation of monoaminergic system (serotonergic and adrenergic), and this represents the mechanism of the antidepressant activity of EA $[59,60]$. The intimate mechanism by which EA could manipulate the monoaminergic system has remained obscure. It may deplete the MAO enzymes causing a rise in the quantity of monoamines stored and released from the nerve terminals [61].

In this study, serum ferritin and HO-1 levels displayed significant elevation in GU group. Ferritin is the major storage protein in the body for iron and the most powerful marker for diagnosis of iron deficiency anemia [62]. Ferritin is affected by iron deficiency as it reaches to $12-15 \mathrm{ng} / \mathrm{ml}$ without concomitant inflammation and to move than 50 $\mathrm{ng} / \mathrm{ml}$ with concomitant inflammation [63]. Blood loss due to gastric lesions and the inhibition of iron absorption as a result of the elevated $\mathrm{pH}$ of gastric juice is responsible for the onset of anemia in peptic ulcer patients [64].

Pre-treatment of GU bearing rats with Omeprazole elicited significant regression in serum ferritin level. On the experimental level, it was observed that PPI therapy decreases the absorption of iron in animals feeding diet with low iron [65]. On the clinical level, patients with longterm treatment with PPI experienced a decrease in iron absorption with a concomitant decrease in serum ferritin level [66]. PPI administration could decrease the absorption of non-heme iron from diet, and chronic PPI administration leads to a significant reduction in the yearly blood volume that needed to be removed to maintain body iron stores at the proper level [67].

Treatment with Qu prior GU induction evoked significant decline in serum ferritin level. Qu is known as an iron chelator, and it is able to decrease ferritin level in Caco-2 cells in vitro. Acute exposure of rat duodenal mucosa to $\mathrm{Qu}$ elevates apical iron uptake but reduces subsequent basolateral iron efflux into the circulation. Qu binds iron between its 3-hydroxyl and 4-carbonyl groups and the methylation of the 3-hydroxyl group negates both the increase in iron apical uptake and the inhibition of basolateral iron release, indicating that the acute action of $\mathrm{Qu}$ on iron transport may be attributed to iron chelation. The increase in duodenal iron content presents an apparent paradox due to, in Qu-treated Caco-2 cells, a significant reduction in ferritin levels has been observed suggesting a functional cellular iron deficiency rather than iron loading [68].

Treatment with EA before the onset of GU in the present study resulted in significant decrease in serum ferritin levels. Polyphenolic compounds present in the diet possess a wide spectrum of actions in vivo and in vitro, involving chelation of elements such as iron. It has been found that polyphenols suppress the absorption of non-heme iron by inhibiting basolateral iron present rather than by reducing apical iron import in the intestinal cells [69].

GU bearing rats exhibited a significant increase in serum HO-1 level. It has been observed that the expression of HO-1 is upregulated during the inflammatory phase in rats administered acetic acid for induction of GU [70]. HO-1 was reported to possess cytoprotective and antiinflammatory properties. Its expression is paralleled by the resolution of non-immune as well as immune-driven inflammation [71]. The role of HO- 1 as anti-inflammatory defensive mediator may be attributed to its conversion of oxidant heme to antioxidant biliverdin and bilirubin. It also increases the level of intracellular free iron to facilitate ferritin upregulation [72].

Pre-treatment with Omeprazole in GU bearing rats caused significant decrease in serum HO-1 level. PPIs have a gastroprotective effect, independent on their antisecretory actions [73], which is probably mediated by inhibition of neutrophil functions as well as antioxidant actions [74]. The effect of PPIs on HO-1 induction remain controversial; Becker et al. [75] showed that both Omeprazole and Lansoprazole strongly induce HO-1 expression in gastric epithelial cells in vitro, while Takagi et al. [76] mentioned that Omeprazole weakly induces the expression of HO-1 in gastric epithelial cell lines. Yoda et al. [77] study, on the rat small intestine, was consistent with that of Takagi et al. [76] in gastric epithelial cells. The present finding pointed to the reduction of HO-1 level in serum of Omeprazole-administered rats indicating the anti-inflammatory effect of Omeprazole. However, further studies are needed to clarify these discrepancies regarding the effect of PPIs on HO-1 induction.

Treatment with Qu prior GU induction in rats caused significant decrease in serum HO-1 level. Qu has been found to activate cellular antioxidant system by increasing both transcriptional and post-transcriptional levels of $\mathrm{Nrf}-2$, a transcription factor which induces expression of various antioxidants and Phase II detoxifying enzymes including NADPH quinone oxidoreductase 1, glutamate cysteine ligase, HO-1, and many others [78]. At the same time, Qu has been shown to reduce the level of Keap1 that keeps Nrf-2 in cytoplasm and thus blocks its activity through the modification of Keap1 protein rather than $26 \mathrm{~S}$ proteasome degradation [79]. These mechanisms explain the depletion in serum HO-1 level on pre-treatment with Qu in GU bearing rats in the current study.

Treatment with EA prior GU induction in rats evoked significant decline in serum HO-1 level. Garhy et al. [80] have been demonstrated that the renoprotection offered by EA is related to the inhibition of HO-1 that is elevated in the kidney following cisplatin-induced nephrotoxicity. Therefore, the diminished HO-1 level following EA administration could be a consequence of the antioxidant/free radical scavenging effect and the suppression of transcriptional activation of NF- $\kappa B$, in addition to the anti-inflammatory property of EA [81].

In this study, GU group exhibited significant rise in serum IL-2 level. Chuian et al. [82] proved that IL-2 shows significant increase during stress-induced GU. IL-2 release is controlled by CD4(+) CD25(+) regulatory $\mathrm{T}$ cells. In a chronic restraint stress mice model, the inhibition of CD4+ CD25+ regulatory T cells by anti-CD25 antibodies induced a significant increase in plasma IL-2 [83]. Moreover, IL-2 is also thought to potentiate $H$. pylori-associated gastroduodenal disorders by controlling Th1 immune responses [84].

Pre-treatment of GU bearing rats with Omeprazole evoked significant drop in serum IL-2 level. Kountouras et al. [85] mentioned that Omeprazole controls cytokine pattern in subjects with DU disorder. This study proved that the marked downregulation of the proinflammatory cytokines, particularly the common inflammatory cytokine IL-2, indicates that the potential cytokine synthesis of the Th1 profile from peripheral blood lymphocytes is significantly inhibited after Omeprazole therapy.

GU group pre-treated with $\mathrm{Qu}$ showed an insignificant decline in serum IL-2 level. Qu is proposed to manipulate different inflammatory responses of macrophages and $\mathrm{T}$ lymphocytes. Despite the antiinflammatory function of Qu through acting on Th cells, the exact mechanism remains unclear. It has been found that Qu suppresses both interferon gamma and IL-2 production on T cell receptor stimulation. Furthermore, $\mathrm{Qu}$ could diminish the expression of $\mathrm{IL}-2$, which is essential for positive regulatory loop of IL-2 autoactivation [86].

EA treatment prior induction of GU in rats led to an insignificant decrease in serum IL-2 level. Kaul et al. [87] cited that EA possesses 
anticarcinogenic and anti-inflammatory properties. These investigators recorded a significant drop in IL-2 and INF $\gamma$ expression in EA-treated Jurkat $\mathrm{T}$ cells. This finding pointed to the link between EA-mediated attenuation of $\mathrm{Ca}^{2+}$ influx and the alteration in cytokine expression. Thus, the anti-inflammatory action of EA could be attributed to its ability to mitigate $\mathrm{Ca}^{2+}$ influx with consequent downregulation of cytokine expression.

In this study, significant amplification in serum AGEs level has been registered in GU bearing rats. It has been reported that the induction of GU increases the immunohistochemical staining of cytoplasmic high-mobility group box 1 (HMGB1) and elevates serum HMGB1 levels. HMGB1 was initially discovered as a nuclear protein that interacts with DNA as a chromatin-associated non-histone protein to stabilize nucleosomes and to regulate the transcription of several genes in the nucleus. Once actively secreted into the extracellular environment, HMGB1 stimulates inflammatory axis by activating multiple receptors, involving toll-like receptor 2 (TLR2)s, TLR4, and receptor for advanced glycation end products resulting in tissue injury [88].

Omeprazole treatment prior induction of GU in rats caused a significant drawback in serum AGEs level. It has been reported that a single dose of PPIs prevents the thioglycollate-induced peritoneal infiltrate of inflammatory cells. Thioglycollate is stimulated by non-enzymatic reactions between proteins and the reduced sugars causing the formation of AGEs [89]. This indicates that PPIs are a good line of therapy for various types of inflammation.

Pre-treatment of GU rats with $\mathrm{Qu}$ led to insignificant reduction in serum AGEs level. Methylglyoxal (MGO) and glyoxal (GO) are considered to be precursor of AGEs. Therefore, diminishing the levels of MGO would be an effective modality to decrease the generation of AGEs. Qu could upregulate the expression of glyoxalase I and II and GSH/GSH disulfide ratio to potentiate the detoxification of MGO [90]. Furthermore, Qu has been reported to strongly suppress the production of AGEs in a dosedependent manner through trapping reactive dicarbonyl compounds. In bovine serum albumin-MGO/GO system, Qu could trap MGO and GO directly and then significantly inhibited the generation of AGEs [91].

GU bearing rats pre-treated with EA experienced an insignificant decrease in serum AGEs level. EA was reported to have anti-glycation activity by reducing the formation of AGEs [92,93]. EA has been found to inhibit MGO and AGE metabolite, which might be one of the possible mechanisms for its inhibitory effects on AGEs formation. EA could suppress AGEs accumulation in the kidney of diabetic rats and ameliorate AGE-mediated pathogenesis of diabetic nephropathy [94].

Rat group afflicted with peptic ulcer experienced a significant decrease in serum FN level. FN is found in the mucosal epithelial basement membrane. It is a multifunctional extracellular matrix protein that plays an important role in cell proliferation, adhesion, and migration, all components of the healing process. Levitan et al. [95] stated that exacerbation of ulcer occurs parallel to the significant reduction in FN concentration which tends to be increased with ulcer healing.

Pre-treatment of GU bearing rats with Omeprazole resulted in insignificant increase in serum FN level. Ghebremariam et al. [96] cited that PPIs regulate fibrosis marker like soluble collagen, in idiopathic pulmonary fibrosis patients. Moreover, it has been demonstrated that many signaling axis that is known to be implicated in inflammatory process and fibrosis involving members of the collagen family ( $\operatorname{Col} 1 \alpha 2$, Col3 $\alpha 1$, and Col16 1 ), FN, and matrix metalloproteinases (MMPs) (MMP12) are regulated by PPIs.

Treatment with $\mathrm{Qu}$ prior induction of $\mathrm{GU}$ produced insignificant amplification in serum FN level. Qu could enhance the production of both collagen and FN which made Qu to be helpful in arthritis, aging as well as wound healing [97]. Qu displays many pharmacological activities in the gastroprotective area, functioning as antisecretory, cytoprotective, and antioxidant agent. Thus, it helps in healing process of GUs [98].

GU group pre-treated with EA displayed insignificant enhancement in serum FN level. EA is able to accelerate healing in indomethacin GU model [32]. Thus, EA may promote GU healing by increasing collagen and FN production.

Microscopic examination of section of the stomach tissue of rat administered aspirin revealed necrosis of the surface mucous cells and fundus glands as well as hemorrhage in the mucosal layer. Moreover, the mucous cells appeared to be pyknotic and desquamated from mucosa and the necrosis extended to the body of the fundus glands. Moreover, histochemical investigation of stomach tissue section of GU bearing rat showed mucus production in the surface epithelial and mucous neck cells as manifested by the pale or depletion of stainability. $\mathrm{GU}$ is a common disease, and the manifestation of the disease is shared by other inflammatory disorders in the gut, i.e., the migration of activated neutrophils and macrophages are the major components of active lesions in ulceration [99]. Many of neutrophils and macrophages enter the injured mucosa during acute inflammation, resulting in overproduction of oxygen free radicals [100], damaging the gastric mucosa and induction of perforations that lead to bleeding [32].

Histological examination of stomach tissue section of GU bearing rat pre-treated with Omeprazole showed areas of hemorrhage and a little degenerative superficial epithelial cells and the remaining appeared more or less like control. Furthermore, histochemical examination of stomach tissue section of rat in this group showed an increase in the polysaccharides the surface epithelium and the mucous neck cells of the gastric mucosa. The degenerative parts of the mucosa displayed weak stainability. Walan et al. [101] have been showed that Omeprazole blocks the action of $\mathrm{H}^{+}, \mathrm{K}^{+}$ATPase in the gastric mucosa and thus depletes the secretion of hydrochloric acid.

As indicating from histological findings, pre-treatment with $\mathrm{Qu}$ could preserve the cytoarchitecture of the entire gastric mucosa. Qu displayed not only the preservation but also the regeneration of gastric mucosa in the injured regions. Previous histological study on the stomach tissue section revealed that flavonoids cause rise in mucus production [102]. The anti-ulcerogenic potential of flavonoids which is associated with the elevated mucus secretion has been established by Beil et al. [17] and Khayyal et al. [103]. Therefore, the increased levels of adherent mucus content of gastric tissue of rat pre-treated with Qu in this study indicated its cytoprotective action on experimentally induced GU. The elevated total carbohydrate:protein (TC:P) ratio of rat in this group as manifested by the increased polysaccharide content in histochemical examination is considered as the direct reflection of mucin activity [104]. The wide distribution of adherent mucus content in the GI tract plays a critical role in cytoprotection and repairment of the gastric mucosa [105]. In addition, $\mathrm{Qu}$ has been reported to inhibit hog gastric $\mathrm{H}^{+}, \mathrm{K}^{+}$-ATPase, and $\mathrm{K}^{+}$-stimulated/j-nitrophenyl phosphatase activity in a dose-dependent manner. The inhibition of $\mathrm{H}^{+}, \mathrm{K}^{+}$-ATPase by Qu is competitive with ATP and is noncompetitive with $\mathrm{K}^{+}$. Thus, $\mathrm{Qu}$ can reduce the phosphorylated enzyme level by competition with ATP, and thereby inhibit the $\mathrm{H}^{+}, \mathrm{K}^{+}$ATPase activity [106].

Photomicrograph of stomach tissue section of GU bearing rat pretreated with EA showed little degenerative epithelial cells, and the remaining appeared more or less like control. Furthermore, histochemical examination of stomach tissue section of rat in this group showed that the heterogeneous staining is encountered, where the degenerated surface epithelial cells are almost devoid of stainable material, and the outer half of the mucosa is densely stained. EA showed its ability to promote healing in indomethacin-induced GUs in mice due to its capability to reduce neutrophils infiltration. The modulation of COX-pathway by EA helps in upregulating mucosal growth factors levels and preserving the balance of pro-/anti-inflammatory cytokines level to stimulate ulcer healing [32]. Furthermore, EA showed a marked 
inhibitory effect on acid secretion and occurrence of stress-induced gastric lesions, and these effects have been suggested to be attributed to the inhibition of $\mathrm{H}+, \mathrm{K}(+)$-ATPase activity [107].

Summing up, the results of the current study shed light on the significant anti-ulcer activity of Qu and EA in GU rat model. Notably, Qu exhibited more pronounced effect on GU healing than EA, which appears from gross evaluation test, biochemical analyses, histopathological examination and histochemical determination of polysaccharides. A protection afforded by $\mathrm{Qu}$ and EA against GU was likely attributable to their anti-stress potential, antioxidant activity, iron chelating property, anti-inflammatory action, and cytoprotective efficacy.

\section{ACKNOWLEDGMENT}

The authors appreciate the staff members of Pathology Department, Medical Research Division, National Research Centre, Egypt, for their kind support and effort in performing the histological and histochemical part of this manuscript.

\section{REFERENCES}

1. Ghosh CK, Khan MR, Alam F, Shil BC, Kabir MS, Mahmuduzzaman M, et al. Peptic Ulcer disease in Bangladesh: A multi-centre study. Mymensingh Med J 2017;26:141-4.

2. Sharma D, Bhatt S. A comprehensive review on ulcer healing potential of medicinal plants. Int J Pharm Pharm Sci 2014;16 Suppl 10:1-9.

3. Casa CL, Villegas I, Lastra CA, Motilva V, Calero MJ. Evidence for protective and antioxidant properties of rutin, a natural flavone, against ethanol induced gastric lesions. J Ethnopharmacol 2000;71:45-53.

4. Ray R, Chaudhuri R, Majumdar B, Bandyopadhyay S. Antioxidant activity of ethanol extract of rhizome of Picrorhiza kurroa on indomethacin induced gastric ulcer during healing. Indian $\mathrm{J}$ Clin Biochem 2002;17 Suppl 2:44-51.

5. Mallika J, Shyamala S. Antioxidant effect of methanolic extract of Solanum nigrum berries on aspirin induced gastric mucosal injury. Indian J Clin Biochem 2004;19 Suppl 1:57-61.

6. Cuzick J, Thorat MA, Bosetti C. Estimates of benefits and harms of prophylactic use of aspirin in the general population. Ann Oncol 2015;26 Suppl 1:47-57.

7. Hern S, Ez-Dia Z, Rodriguez LA. Cardio protective aspirin users and their excess risk of upper gastrointestinal complications. BMC Med 2006;4:22.

8. Dajani EZ, Klamut MJ. Novel therapeutic approaches to gastric and duodenal ulcers: An update. Expert Opin Investig Drugs 2000;9:1537-44.

9. Shin JM, Sachs G. Pharmacology of proton pump inhibitors. Curr Gastroenterol Rep 2008;10:528-34.

10. Robinson M, Horn J. Clinical pharmacology of proton pump inhibitors: What the practicing physician needs to know. Drugs 2003;63:2739-54.

11. Kedika RR, Souza RF, Spechler SJ. Potential anti-inflammatory effects of proton pump inhibitors: A review and discussion of the clinical implications. Dig Dis Sci 2009;54:2312-7.

12. Nathiya S, Durga M, Thiyagarajan D. Quercetin, encapsulated querxcetin and it application-a review. Int $\mathrm{J}$ Pharm Pharm Sci 2014;6:20-4.

13. Haleagrahara N, Radhakrishnan A, Lee N, Kumar P. Flavonoid quercetin protects against swimming stress-induced changes in oxidative biomarkers in the hypothalamus of rats. Eur J Pharmacol 2009;621:46-52.

14. Chan HM, Zhu LF, Zhong R, Grant D, Goyer RA, Cherian MG. Nephrotoxicity in rats following liver transplantation from cadmiumexposed rats. Toxicol Appl Pharmacol 1993;123:89-96.

15. Tauber AI, Fay JR, Marletta MA. Flavonoid inhibition of the human neutrophil NADPH-oxidase. Biochem Pharmacol 1984;33:1367-9.

16. Bureau G, Longpre F, Martinoli MG. Resveratrol and quercetin, two natural polyphenols, reduce apoptotic neuronal cell death induced by neuroinflammation. J Neurosci Res 2008;86:403-10.

17. Beil W, Birkholz C, Sewing KF. Effects of flavonoids on parietal cell acid-secretion, gastric mucosal prostaglandin production and Helicobacter pylori growth. Arzneim Forsch 1995;45:697-700.

18. Charest M, Belair MA. C13 urea breath test accuracy analysis against former $\mathrm{C} 14$ urea breath test technique: Is there still a need for an indeterminate result category. J Nucl Med Technol 2017;45 Suppl 2:87-90.
19. Vattem DA, Shetty K. Biological functionality of EA: A review. J Food Biochem 2005;29:234-66.

20. Khanduja KL, Gandhi RK, Pathania V, Syal N. Prevention of $\mathrm{N}$-nitrosodiethylamine-induced lung tumorigenesis by ellagic acid and quercetin in mice. Food Chem Toxicol 1999;37:313-8.

21. Rogerio AP, Fontanari C, Borducchi E, Keller AC, Russo M, Soares EG, et al. Anti-inflammatory effects of Lafoensia pacari and ellagic acid in a murine model of asthma. Eur J Pharmacol 2008;580:262-70.

22. Soh PN, Witkowski B, Olagnier D, Nicolau ML, Garcia-Alvarez M, Berry A, et al. In vitro and in vivo properties of ellagic acid in malaria treatment. Antimicrob Agents Chemother 2009;53:1100-6.

23. Bae JY, Choi JS, Kang SW, Lee YJ, Park J, Kang YH. Dietary compound ellagic acid alleviates skin wrinkle and inflammation induced by UV-B irradiation. Exp Dermatol 2010;19:182-90.

24. Chao CY, Mong MC, Chan KC, Yin MC. Anti-glycative and antiinflammatory effects of caffeic acid and ellagic acid in kidney of diabetic mice. Mol Nutr Food Res 2010;54:388-95.

25. Han DH, Lee MJ, Kim JH Antioxidant and apoptosis inducing activities of EA. Anticancer Res 2006;26:3601-6.

26. Iino T, Nakahara K, Miki W, Kiso Y, Ogawa Y, Kato S, et al. Less damaging effect of whisky in rat stomachs in comparison with pure ethanol. Digestion 2001;64:214-221.

27. Chatterjee A, Chatterjee S, Bandyopadhyay SK. H. pylori-induced gastric ulcer: Pathophysiology and herbal remedy. Int J Biol Med Res 2012;3:1461-5

28. Ogawa Y, Kanatsu K, Iino T, Kato S, Jeong YI, Shibata N, et al. Protection against dextran sulfate sodium-induced colitis by microspheres of ellagic acidin rats. Life Sci 2002;71:827-39.

29. Elsharabasy FS, AL-Mushhin AA, Araffa S, Farrag AH. Phytochemical screening and gastroprotective effect of the aerial parts of salasola terrandra forssk. Against aspirin induced gastric ulceration in rats. J Pharm Phytochem 2015;3 Suppl 6:221-32.

30. Carvalho CA, Fernandesk KM, Matta SL, Silva MB, Oliveira LL, Fonseca CC. Evaluation of antiulcerogenic activity of aqueous extract of Brassica oleracea var. Capitata (CABBAGE) on Wister rat gastric ulceration. Arq Gastroenterol 2011;48 Suppl 4:276-82.

31. Shakeerabanu M, Sujatha K, Rajneesh CP, Manimaran A. The defensive effect of quercetin on indomethacin induced gastric damage in rats. Adv Biol Res 2011;5 Suppl 1:64-70.

32. Chatterjee A, Chatterjee S, Das S, Saha A, Chattopadhyay S, Bandyopadhyay SK. Ellagic acid facilitates indomethacin-induced gastric ulcer healing via COX-2 up-regulation. Acta Biochim Biophys Sin 2012;44:565-76.

33. Van Herck H, Baumans V, Brandt CJ, Boere HA, Hesp AP, Lith HA, et al. Blood sampling from the retro-orbital plexus, the saphenous vein and the tail vein in rats: Comparative effects on selected behavioral and blood variables. Laboratory Anim 2001;35:131-9.

34. Ganguly AK. A method for quantitative assement of experimentally produced ulcers in stomach of rats. Experientia 1969;25:1124.

35. Suzuki Y, Hayashi M, Ito M, Yamagami I. Anti-ulcer effects of 4'-(2-carboxyetyl) phenyl trans-4-aminomethyl cyclohexane carboxylate hydrochloride (cetraxate) on various experimental gastric ulcers in rats. Jpn J Pharmacol 1976;26:471-80.

36. Odell WD, Horton R, Pandian MR, Wong J. The Use of ACTH and Cortisol Assays in the Diagnosis of Endocrine Disorders.: Nichols Institute Publication; 1989.

37. White D, Kramer D, Johnson G, Dick F, Hamilton H. CF: Enzyme immunoassay for the quantitative determination of human ferritin concentration in human serum. Am J Clin Path 1986;72:346.

38. Banchroft JD, Steven A, Turner DR. Theory and Practice of Histological Technique. $4^{\text {th }}$ ed. New York, London, San Francisco, Tokyo: Churchil Livingstone; 1996.

39. Manus JF. Histological demonstration of mucin after periodic acid. Nature 1946;158:202.

40. Armitage P, Berry G. Comparison of several groups. In: Statistical Method in Medical Research. $2^{\text {nd }}$ ed. Oxford: Block well Significant Publication; 1987. p. 186-213.

41. Rao V, Sairam K, Goel RK. Experimental evaluation of Bacopa monniera on rat gastric ulceration and secretion. Indian J Physiol Pharmacol 2000;44:35-41.

42. Lee M, Kallal SM, Feldman M. Omeprazole prevents indomethacininduced gastric ulcers in rabbits. Aliment Pharmacol Ther 1996;10:571-6.

43. Alkushi AG, Elsawy NA. Quercetin attenuates indomethacin-induced acute gastric ulcer in rats. Folia Morphol (Warsz) 2017;76 Suppl 2:252-61

44. Virchenko OV, Falalyeyeva TM, Beregova TV, Maryana SY. The 
multistrain probiotic enhances the healing process of stress-induced lesions of the gastric mucosa of ats. Res J Pharm Biol Chem Sci 2015;6 Suppl 1:249-59.

45. Ohta Y, Kaida S, Chiba S, Tada M, Teruya A, Imai Y, et al. Involvement of oxidative stress in increases in the serum levels of various enzymes and components in rats with water-immersion restraint stress. Clin Biochem Nutr 2009;45 Suppl 3:347-54

46. Filaretova L, Morozova O, Bagaeva T, Podvigina TJ. From gastro protective to proulcerogenic action of glucocorticoids on the gastric mucosa. Physiol Pharmacol 2009;60 Suppl 7:79-86.

47. Berkenbosch F, Oers J, Rey A, Tilders F, Besedovsky H. Corticotropinreleasing factor-producing neurons in the rat activated by interleukin-1. Science 1987;238:524-6.

48. Lam NP, Le PD, Crawford SY, Patel S. National survey of stress ulcer prophylaxis. Crit Care Med 1999;27:98-103

49. Kawabata K, Kawai Y, Terao J. Suppressive effect of quercetin on acute stress-induced hypothalamic-pituitary-adrenal axis response in wistar rats. J Nutr Biochem 2009;21:374-80.

50. Naveen S, Siddalingaswamy M, Singsit D, Khanum F. Anti-depressive effect of polyphenols and omega-3 fatty acid from pomegranate peel and flax seed in mice exposed to chronic mild stress. Psychiatry Clin Neurosci 2013;67:501-8.

51. Al Asmari AA, Arshaduddin M, Elfaki I, Kadasah S, Al Robayan A, Al Asmary S. Aripiprazole an atypical antipsychotic protects against ethanol induced gastric ulcers in rats. Int J Clin Exp Med 2014;7 Suppl 8:2031-44.

52. Debnath S, Biswas D, Ray K, Guha D. Moringaoleifera induced potentiation of serotonin release by 5 -HT3 receptors in experimental ulcer model. Phytomedicine 2011;18:91-5.

53. Cho CH, Lai KH, Ogle CW, Tsai YT, Lee SD, Lo KJ. The role of histamine and serotonin in gastric acid secretion: A comparative study in gastric and duodenal ulcer patients. J Gastroenterol Hepatol 1986;1 Suppl 6:437-42.

54. Lai YC, Ho Y, Huang KH, Tsai LH. Effects of erotonin on acid secretion in isolated rat stomach: The role of $5 \mathrm{HT} 3$ receptors. Chin J Physiol 2009;52:395-405

55. Ji CX, Fan DS, Li W, Guo L, Liang ZL, Xu RM, et al. Evaluation of the anti-ulcerogenic activity of the antidepressants duloxetine, triptyline, fluoxetine and mirtazapine in different models of experimental gastric ulcer in rats. Eur J Pharmacol 2012;691:46-51

56. Gjestad C, Westin AA, Skogvoll E, Spigset O. Effect of proton pump inhibitors on the serum concentrations of the selective serotonin reuptake inhibitors citalopram, escitalopram, and sertraline. Ther Drug Monit 2015;37:90-7.

57. Yoshino S, Hara A, Sakakibara H, Kawabata K, Tokumura A, Ishisaka A, et al. Effect of quercetin and glucuronide metabolites on the monoamine oxidase - A reaction in mouse brain mitochondria. Nutrition 2011;27:847-52.

58. Abdalla FH, Schmatz R, Andréia MC, Carvalho FB, Baldissarelli J, Oliveira JS, et al. Quercetin protects the impairment of memory and anxiogenic-like behavior in rats exposed to cadmium: Possible involvement of the acetyl cholinesterase and $\mathrm{Na}+, \mathrm{K}+-$ ATPase activities. Physiol Behav 2014;135:152-67.

59. Girish C, Raj V, Arya J, Balakrishnan S. Evidence for the involvement of the monoaminergic system, but not the opioid system in the antidepressant-like activity of ellagic acid in mice. Eur J Pharmacol 2012;682:118-25

60. Kalshetti P, Allurib R, Thakurdesaic P. Antidepressant and anti-anxiety effect of ellagic acid from Punica granatum L. rind in olfactory bulbectomy model in rats. Int J Pharm Sci Rev Res 2015;34 Suppl 1:197-204.

61. Xu Y, Ku BS, Yao HY, Lin YH, Ma X, Zhang YH, et al. The effects of curcumin on depressive-like behaviors in mice. Eur J Pharmacol 2005;518:40-6.

62. Eshraghian A. Epidemiology of Helicobacter pylori infection among the healthy population in Iran and countries of the Eastern Mediterranean region: A systematic review of prevalence and risk factors. World J Gastroenterol 2014;20 Suppl 46:17618-25

63. Jamieson JA, Kuhnlein HV. The paradox of anemia with high meat intake: A review of the multifactorial etiology of anemia in the Inuit of North America. Nutr Etiol Rev 2008;66 Suppl 5:256-71.

64. Windle HJ, Kelleher D, Crabtree JE. Childhood Helicobacter pylori infection and growth impairment in developing countries: A vicious cycle? Pediatrics 2007;119:E754-9.

65. Miret S, Simpson RJ, McKie AT. Physiology and molecular biology of dietary iron absorption. Annu Rev Nutr 2003;23:283-301.

66. Sharma VR, Brannon MA, Carloss EA. Effect of omeprazole on oral iron replacement in patients with iron deficiency anemia. South Med J 2004;97:887-9.

67. Hutchinson C, Geissler CA, Powell JJ, Bomford A. Proton pump inhibitors suppress absorption of dietary non-heme iron in hereditary hemochromatosis. Gut 2007;56:1291-5.

68. Lesjak M, Hoque R, Balesaria S, Skinner V, Debnam ES. Quercetin inhibits intestinal iron absorption and ferroportin transporter expression in vivo and in vitro. PLoS One 2014;9 Suppl 7:1-10.

69. Kim EY, Ham SK, Shigenaga MK, Han O. Bioactive dietary polyphenolic compounds reduce nonheme iron transport across human intestinal cell monolayers. J Nutr 2008;138:1647-51.

70. Guo JS, Cho CH, Wang WP, Shen XZ, Cheng CL, Koo MW. Expression and activities of three inducible enzymes in the healing of gastric ulcers in rats. World J Gastroenterol 2003;9 Suppl 8:1767-71.

71. Willis D, Moore AR, Willoughby DA. Hemeoxygenase isoform expression in cellular and antibody-mediated models of acute inflammation in the rat. J Pathol 2000;190:627-34

72. Otterbein LE, Bach FH, Alam J, Soares M, Lu HT, Wysk M, et al. Carbon monoxide has anti-inflammatory effects involving the mitogen-activated protein kinase pathway. Nat Med 2000;6:422-8.

73. Kobayashi T, Ohta Y, Inui K, Yoshino J, Nakazawa S. Protective effect of omeprazole against acute gastric mucosal lesions induced by compound 48/80, a mast cell degranulator, in rats. Pharmacol Res 2002;46:75-84

74. Fornai M, Natale G, Colucci R, Tuccori M, Carazzina G, Antonioli $\mathrm{L}$, et al. Mechanisms of protection by pantoprazole against NSAID-induced gastric mucosal damage. Naunyn Schmiedebergs Arch Pharmacol 2005;372:79-87.

75. Becker JC, Grosser N, Waltke C, Schulz S, Erdmann K, Domschke W, et al. Beyond gastric acid reduction: Proton pump inhibitors induce heme oxygenase-1 in gastric and endothelial cells. Biochem Biophys Res Commun 2006;345:1014-21.

76. Takagi T, Naito Y, Okada H, Ishii T, Mizushima K, Akagiri S, et al. Lansoprazole, a proton pump inhibitor, mediates anti-inflammatory effect in gastric mucosal cells through the induction of heme oxygenase-1 via activation of NF-E2-related factor 2 and oxidation of kelch-like ECH-associating protein 1. J Pharmacol Exp Ther 2009;331:255-64.

77. Yoda Y, Amagase K, Kato S, Tokioka S, Murano M, Kakimoto K, et al. Prevention by lansoprazole, a proton pump inhibitor, of indomethacininduced small intestinal ulceration in rats through induction of heme oxygenase-1. J Physiol Pharmacol 2010;61:287-94.

78. Alrawaiq NS, Abdullah AA. Review of flavonoid quercetin: Metabolism, bioactivity and antioxidant properties. Int J PharmTech Res 2014;6:933-41.

79. Tanigawa S, Fujii M, Hou DX. Action of Nrf-2 and keap1 in AREmediated NQO1 expression by quercetin. Free Radic Biol Med 2007;42 Suppl 11:1690-703.

80. Garhy AM, El-Raouf OM, El-Sayeh BM, Fawzy HM, Abdallah DM. Ellagic acid anti-inflammatory and ant apoptotic potential mediate reno protection in cisplatin nephrotoxic rats. J Biochem Mol Toxicol 2014;28:472-9

81. Al-Kharusi N, Babiker HA, Al-Salam S, Waly MI, Nemmar A, Al-Lawati I, et al. Ellagic acid protects against cisplatin-induced nephrotoxicity in rats: A dose-dependent study. Eur Rev Med Pharmacol Sci 2013;17 Suppl 3:299-310.

82. Chuian OM, Temuriants NA, Makhonina MM, Zaiachnikova TV. Effect of hypokinetic stress and low intensity electromagnetic field of extremely high frequency on changes of cytokine concentration in rat blood. Fiziol Zh 2005;51:70-8.

83. Kim SJ, Lee H, Lee G. CD4+CD25+ regulatory $\mathrm{T}$ cell depletion modulates anxiety and depression-like behaviors in mice. PLoS One 2012;7:e42054.

84. Padol IT, Hunt RH. Effect of Th1 cytokines on acid secretion in pharmacologically characterized mouse gastric glands. Gut 2004;53:1075-81.

85. Kountouras J, Boura P, Lygidakis NJ. Omeprazole and regulation of cytokine profile in Helicobacter pylori-infected patients with duodenal ulcer disease. Hepatogastroenterology 2000;47:1301-4.

86. Yu ES, Min HJ, Ana SY, Wona HY, Hong JH, Hwang ES. Regulatory mechanisms of IL-2 and IFNg suppression by quercetin in T helper cells. Biochem Pharm 2008;76:70-8

87. Kaul S, Murphy M, Morrill J, Mathias C, Thomas D, Bose DD. Ellagic acid mediated attenuation of store operated calcium entry alters cytokine expression in Jurkat T cells. FASEB J 2016;30 Suppl $1: 1138-2$

88. Nadatani $\mathrm{Y}$, Watanabe $\mathrm{T}$, Tanigawa $\mathrm{T}$, Ohkawa $\mathrm{F}$, Takeda $\mathrm{S}$, 
Higashimori A, et al. High-mobility group box 1 inhibits gastric ulcer healing through toll-like receptor 4 and receptor for advanced glycation end products. PLoS One 2013;8 Suppl 11:1-13.

89. Li YM, Baviello G, Vlassara H, Mitsuhashi T. Glycation products in aged thioglycolate medium enhance the elicitation of peritoneal macrophages. J Immunol Methods 1997;201:183-8.

90. Zhao Y, Wang P, Chen H, Sang S. Dietary quercetin inhibits methylglyoxal-induced advanced glycation end products formation in mice. FASEB J 2016;30 Suppl 1:692-4.

91. Li X, Zheng T, Sang S, Lv L. Quercetin inhibits advanced glycation end product formation by trapping methylglyoxal and glyoxal. J Agric Food Chem 2014;62 Suppl 50:12152-8.

92. Muthenna P, Akileshwari C, Reddy GB. Ellagic acid, a new antiglycating agent: Its inhibition of $\mathrm{N}$-(carboxymethyl) lysine. Biochem J 2012;442:221-30.

93. Liu W, Ma H, Frost L, Yuan T, Dain JA, Seeram NP. Pomegranate phenolics inhibit formation of advanced glycation end products by scavenging reactive carbonyl species. Food Funct 2014;5:2996-3004.

94. Raghu G, Jakhotia S, Reddy Y, Kumar A, Reddy GB. Ellagic acid inhibits non-enzymatic glycation and prevents proteinuria in diabetic rats. Food Funct 2016; 7:1574-83.

95. Levitan BN, Perova NI, Astakhin AV, Trubnikov GA. Plasma fibronectin in gastric and duodenal ulcer. Klin Med (Mosk) 1999;77 Suppl 9:31-3

96. Ghebremariam YT, Cooke JP, Gerhart W, Griego C, Brower JB, DoyleEisele M, et al. Pleiotropic effect of the proton pump inhibitor as omeprazole leading to suppression of lung inflammation and fibrosis. J Transl Med 2015;13:249-69.

97. Sharma A, Gupta H. Quercetin-a flavanoid. Chron Young Sci 2010;1 Suppl 1:1-6.

98. Mota KS, Dias GE, Pinto ME, Luiz-Ferreira Â, Souza-Brito AR,
Hiruma-Lima CA, et al. Flavonoids with gastro protective activity. Molecules 2009;14:979-1012.

99. Sasaki S, Hirata I, Maemura K, Hamamoto N, Murano M, Toshina K, et al. Prostaglandin E2 inhibits lesion formation in dextran sodium sulphate-induced colitis in rats and reduces the levels of mucosal inflammatory cytokines. Scand J Immunol 2000;51:23-8.

100. Grisham MB, Granger DN. Neutrophil-mediated mucosal injury; Role of oxygen metabolites. Dig Dis Sci 1988;33:S6-S13.

101. Walan A, Bader JP, Classen M, Lamers C, Piper DW, Rutgersson $\mathrm{K}$, et al. Effect of omeprazole and ranitidine on ulcer healing and relapse rates in patients with benign gastric ulcer. $\mathrm{N}$ Engl J Med 1989;320:69-75.

102. Magistretti MJ, Conti M, Cristoni A. Antiulcer activity of an anthocyanidin from Vaccinium myrtillus. Arzneimittel Forschung 1988;38:686-90.

103. Khayyal MT, el-Ghazaly MA, Kenawy SA, Seif-el-Nasr M, Mahran LG, Kafafi YA, et al. Antiulcerogenic effect of some gastro intestinally acting plant extracts and their combination. Arzneimittel Forschung 2001;51:545-53.

104. Goel RK, Maiti RN, Mukobandhyay K. Effect of tamra bhasma, an Indian indigenous preparation of copper on rat gastric mucosal resistance. Indian J Exp Biol 1994;32:559-61.

105. Tanaka H, Kosaka N, Tomaru A, Shuto K, Oghihara T, Sato N. Augmentation of the gastric mucosal defense mechanism induced by KW - 5805, a novel antiulcer agent. Scand J Gastroenterol 1989;24:170-3

106. Murakami S, Muramatsu M, Otomo S. Inhibition of gastric $\mathrm{H}+\mathrm{K}+$ ATPase by quercetin. J Enzyme Inhib 1991;5 Suppl 4:293-8.

107. Murakami S, Isobe $\mathrm{Y}$, Kijima $\mathrm{H}$, Otomo S. Inhibition of gastric $\mathrm{H}+, \mathrm{K}$ + -ATPase and acid secretion by ellagic acid. Planta Medica 1991;57 Suppl 4:305-8. 